\title{
A study on the issues of undergraduates' Time Management: Take TUFE as an example
}

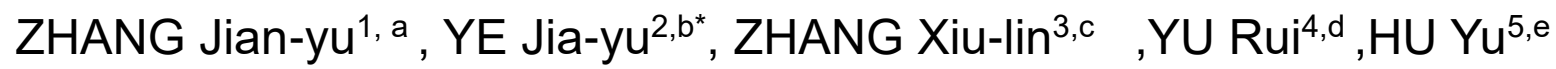 \\ 1 School of Business, Tianjin University and Finance and Economics, Tianjin, China \\ 2345 Department of Business Administration, Tianjin University and Finance and Economics, \\ Tianjin, China \\ aawish@126.com, b*13920977805@163.com , c a2016112651@163.com, \\ d18322295718@163.com, e13102128350@163.com
}

Keywords: Spare time; Time allocation; Sophomore students

\begin{abstract}
Currently, undergraduates' time is free besides the compulsory courses. Therefore, undergraduates have much options for their time allocation. Existing Research shows that arranging time reasonably will promote undergraduates' future's career. Taking 232 sophomore students from Tianjin University of Finance and Economics as an example, this study tries to find their common characteristics and existing problems on time allocation by observing their daily life. In terms of above results, we put forward some suggestions to improve time management for administrators and undergraduates in universities.
\end{abstract}

\section{新时代大学生时间分配的问题与对策研究 以天津财经大学大二学生为例 \\ 张建宇 $1 \mathrm{a}$, 叶家裕 $2 b^{*}$, 张秀林 $3 c$, 余瑞 $4 d$, 胡钰 $5 e$ \\ 1 天津财经大学商学院, 天津, 中国 2345 天津财经大学商学院企业管理系, 天津, 中国 \\ aawish@126.com, b¹3920977805@163.com , c a2016112651@163.com, d18322295718@163.com, e13102128350@163.com}

关键词：闲暇时间，时间分配，大二学生

摘要: 大学生属于自主学习的群体, 在学分课程之外的时间相对自由, 因此在时间上大学生 有极大的自由度和自主性。已有研究表明, 合理时间安排和管理将能够推动学生未来职业生 涯的良性发展。本研究以天津财经大学 232 名大二学生为例, 在观察他们日常活动得的基础 上, 试图发现他们在时间安排上的共性特征和存在问题, 以此为依据为管理者、学生群体提 出有针对性的时间管理改善建议。

\section{1.引言}

当前大学生整体闲暇时间较多且有增多的趋势（季海群，2013），这直接引致近 20 年来 对大学生闲暇时间管理研究增多, 而在性别上男性闲暇时间的感觉要多于女性。当前大学生 闲暇时间多，但时间分配效率不高。2000 年以来，对大学生闲暇时间的利用和管理的研究增 多, 这也从最终的研究生入学的性别比例趋势上可见一斑, 近年来硕士生入学的女性比例逐 渐增加。研究表明, 课余时间安排有助于缓解大学生的心理问题、提高其自主学习能力、提 
高个人综合素质和个人成才 (卫聪聪, 司睿, 2015 )。研究大学生时间利用现状, 可反映大学 生的培养与个人发展存在的问题。本研究选取天津财经大学 250 名大二学生, 通过其一周的 活动内容和时间记录, 研究当下大学生时间分配状况, 样本中男女比例为 $1: 3$, 符合该校的男 女比例。收回 250 份时间记录, 剔除无效记录 18 份, 最终采用记录为 232 份发现了了大学生 在时间安排上的一些特征，本文据此发现并分析了一些问题，并提出了相关建议。

\section{2. 当前大学生时间安排现状及分析}

1. 大学生闲暇时间占比较高

从本文的调查来看，大学生的上课时间仅占工作日的 $17 \%$ ，闲暇时间占绝对比重，尤其 周末时间完全处于闲暇状态。 $50 \%$ 以上的学生将这一时间用于上网消磨时间, 有时则是无所 事事的消极状态。

2.时间安排呈现无意识状态，手机占据太多时间。

大学生的时间安排除了必须要的睡觉外, 主要表现在玩手机、上课、课后的学习上时间 上, 其基本的分配状况如图 1 所示。显然大学生的时间呈现一种被动的碎片化状态, 这其中 玩手机所占的时间甚至超过了课堂和课后学习的时间。

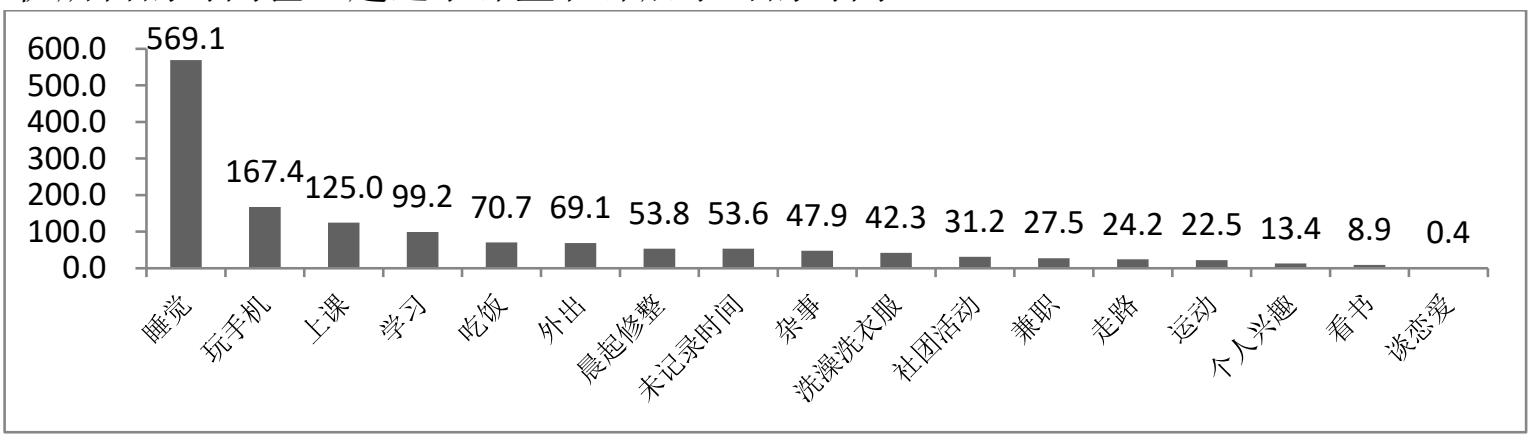

图 1 大学生一周平均时间分配

根据我们的访谈和调查,大学生在课余时间的安排上并没有认真的考虑，仅有 $12 \%$ 的同 学认真安排, $38 \%$ 的同学稍做安排, 而其余的占一半的同学是对课余 时间基本不安排或随心 所欲 (赵丽娜, 2009)。我们的调研中发现未被记录的时间占 3.76\%, 反映大学生无目标状态 明显, 时间安排意识不强, 许多学者由此提出高校加强大学生自主管理时间教育。

\section{3. 大学生时间管理的困境与难题}

1.学生对于时间管理缺少目标导向。大学生在闲暇时间经常从事增进知识的活动 $34.6 \%$, 从事发展能力的活动占 $38.9 \%$, 从事各种娱乐活动占 $57.4 \%$, 还有近 $25 \%$ 的大学生不知道 该如何度过闲暇时间，靠睡觉、闲逛来消磨时光（于昆，2009）。大多数大学生认为课余时间 应该休闲娱乐，无目标状态明显。

2.缺少计划与严格的执行。调查显示，30.38\%的大学生对自己的课余时间不安排、没计 划, 53.16\%的大学生课余时间有安排但执行力度不足, $89.87 \%$ 的大学生有理想中的课余生活 规划,但也并未实际执行（卫聪聪，司睿，2015)。反映大学生时间管理意识低及自控力差。

3. 大学闲暇时间教育的“滞后”。由于高校教育理念的偏失、闲暇教育自身的失误、闲暇教 育资源的不足 (于昆, 2009), 时间管理教育的缺失加重大学生时间管理存在的问题。

\section{4. 大学生现有时间安排的特征与成因}

本研究将学生的活动分为常规活动、自修、娱乐、未记录时间。常规活动包括晨起修整、 
吃饭、洗澡洗衣服、杂事、睡觉、上课、走路。自修包括运动、社团活动、看书、兼职、学 习。娱乐包括玩手机或电脑、外出。研究发现大二学生时间分配特征如下:

\section{1 特征}

1.男生娱乐时间占比较高。

分类对比男女生在工作日与周末四类活动的时间总值与百分比, 由表 1 所示。工作日中 男生的娱乐时间所占的百分比 16.74\%几近女生所占 $8.8 \%$ 的两倍; 周末男生娱乐时间占比较 女生高将近 3\%。与廖婷婷, 林川 (2011) 的研究结果一致, 男生网络成瘾得分显著高于女生。 工作日中女生的自修时间为 195.68 分钟，比男生的 132.32 分钟高 4\%; 而周末的自修时间性 别差异不大，但女生仍比男生平均多 9 分钟。

表 1 时间分配总值与比重表

\begin{tabular}{|c|c|c|c|c|c|c|c|c|}
\hline \multicolumn{9}{|c|}{ 时间分配总值 (min) 与比重表 } \\
\hline \multirow{3}{*}{ 活动 } & \multicolumn{4}{|c|}{ 工作日 } & \multicolumn{4}{|c|}{ 周末 } \\
\hline & \multicolumn{2}{|c|}{ 男生 } & \multicolumn{2}{|c|}{ 女生 } & \multicolumn{2}{|c|}{ 男生 } & \multicolumn{2}{|c|}{ 女生 } \\
\hline & 总值 & 百分比 & 总值 & 百分比 & 总值 & 百分比 & 总值 & 百分比 \\
\hline 常规活动 & 970.73 & $62.40 \%$ & 1028.98 & $65.94 \%$ & 835.88 & $57.61 \%$ & 842.74 & $59.06 \%$ \\
\hline 娱乐 & 260.38 & $16.74 \%$ & 137.28 & $8.80 \%$ & 323.44 & $22.29 \%$ & 281.72 & $19.74 \%$ \\
\hline 自修 & 132.32 & $8.51 \%$ & 195.68 & $12.54 \%$ & 167.86 & $11.57 \%$ & 175.17 & $12.28 \%$ \\
\hline 未记录时间 & 192.13 & $12.35 \%$ & 198.46 & $12.72 \%$ & 123.63 & $8.52 \%$ & 127.35 & $8.92 \%$ \\
\hline
\end{tabular}

2. 参加社团活动的学生时间利用界限模糊。

分类对比是否参加社团学生在工作日与周末四类活动的时间占比，如表 2 所示。本研究 发现, 未记录的时间可以反映学生对于个人时间分配利用情况的了解。参与社团学生未记录 时间明显更多, 在工作日和周末分别比未参与社团学生高 $4.26 \%$ 和 $1.49 \%$ 。 , 参加社团学生时 间利用的界限模糊。

表 2 是否参加社团学生时间分配对比

\begin{tabular}{c|c|c|c|c}
\hline \multicolumn{4}{|c}{ 是否参加社团学生时间分配对比 } \\
\hline \multirow{2}{*}{ 活动 } & \multicolumn{2}{|c}{ 工作日 (周一至周五) } & \multicolumn{2}{c}{ 周末（周六日） } \\
\cline { 2 - 5 } & 参加社团活动 & 未参加社团活动 & 参加社团活动 & 未参加社团活动 \\
\hline 常规活动 & $68.18 \%$ & $73.32 \%$ & $61.94 \%$ & $59.13 \%$ \\
\hline 娱乐 & $12.99 \%$ & $14.44 \%$ & $20.76 \%$ & $20.42 \%$ \\
\hline 自修 & $14.52 \%$ & $12.18 \%$ & $12.93 \%$ & $17.58 \%$ \\
\hline 未记录时间 & $4.32 \%$ & $0.06 \%$ & $4.36 \%$ & $2.87 \%$ \\
\hline
\end{tabular}

3.周末应该娱乐的观念根深蒂固，大学生的时间管理缺乏引导。

由于天津财经大学属于天津市属高校，其中本市学生占有一定的比重，天津市内大学生 周末常选择回家似乎成为这些学生大学生活的常态。本研究将天津市内外的大学生做了分类 比较, 对比发现在工作日与周末的时间分配的总值与所占百分比, 具体结果如表 3 所示。根 据表 3, 我们发现在工作日, 天津市市内外学生各项活动时间总值差距均在 20 分钟以内, 比 重差距均在一个百分点内, 时间分配差异不大。而在周末, 时间分配差距较明显的部分在于 自修时间，较工作日增加 2\%，其余差异不大。 
表 3 本市大学生与外市大学生时间分配对比

\begin{tabular}{c|c|c|c|c|c|c|c|c}
\hline & \multicolumn{6}{c}{ 本市大学生与外市大学生的时间分配对比 } \\
\hline \multirow{2}{*}{ 活动 } & \multicolumn{3}{|c|}{ 工作日 } & \multicolumn{3}{c}{ 周末 } \\
\cline { 2 - 9 } & \multicolumn{2}{|c|}{ 市内 } & \multicolumn{2}{|c|}{ 市外 } & \multicolumn{2}{c}{ 市内 } & \multicolumn{2}{|}{ 市外 } \\
\cline { 2 - 9 } & 总值 & 百分比 & 总值 & 百分比 & 总值 & 百分比 & 总值 & 百分比 \\
\hline 常规活动 & 998 & $69.99 \%$ & 1013 & $68.99 \%$ & 873.3 & $64.02 \%$ & 855 & $59.46 \%$ \\
\hline 自修 & 173.3 & $12.15 \%$ & 179 & $12.19 \%$ & 194.8 & $14.28 \%$ & 234 & $16.27 \%$ \\
\hline 娱乐 & 233.1 & $16.35 \%$ & 226.4 & $15.42 \%$ & 271.7 & $19.92 \%$ & 290 & $20.17 \%$ \\
\hline 未记录时间 & 21.5 & $1.51 \%$ & 50 & $3.41 \%$ & 24.3 & $1.78 \%$ & 59 & $4.10 \%$ \\
\hline
\end{tabular}

\section{2 成因}

1.大多数男生将闲暇时间用于玩手机、电脑。而女生更注重个人提升类活动以填充闲暇 时间。所以男生的娱乐时间多，女生的自修时间多。女生在周末常会外出逛街或游玩，娱乐 时间在周末的性别差异不明显。

2. 社团活动的特性使学生的时间利用界限模糊。社团活动主要以任务为中心，社团成员 围绕任务完成各项工作。社团活动需要思考、探讨的部分较多, 不断渗透进学生的时间分配 中，使其时间分配界限较模糊。

3.社会的娱乐休闲观念影响深远，所处环境对娱乐时间影响不大。周末应该娱乐、放松 的观念深重, 周末市内同学在家会增加休息和常规活动时间, 而市外学生也会选择增加睡觉、 玩手机或电脑时间达到放松的目的。

\section{5. 结论与建议}

1.为了大学生高效的时间管理, 管理者需要激发学生兴趣, 提升安排的主动性。

高校应积极推进社团建设, 多开放体育馆、增设体育健材, 改善图书馆环境和设施的建 设等, 使学生更多地参与到兴趣活动中, 主动地分配时间。通过激发学生兴趣, 使其放下手 机, 多参与有益活动。

2.为提升时间管理的有效性，学校需要强化过程监督、落实过程和结果淘汰机制。

学校可通过强化考勤制度; 增加期中考试; 将社会实践、体能运动与评优考核挂钩; 增 加结果淘汰机制增强学生之间的相互竞争, 改善学习氛围。

3.为减少时间管理的无序性，学校可考虑确立小班制、导师制、高低年级联动制等。

通过小班制、班组制创设相互监督的小环境，采取导师制指导学生选择发展目标，树立 正确的时间观。高低年级联动制促使学生了解高年级的任务及挑战，促进时间分配。

\section{References}

[1] WEI Cong-cong, SI Rui. Status Quo and Countermeasures of College Students' Spare Time Management_- Taking an Agriculture University as an Example). Journal of Taiyuan University (Natural Science Edition). vol.03, pp.21-23,2015. (in Chinese)

[2] LIAO Ting-ting, LIN Chuan.The relationship between time management disposition and internet-addiction disorder among college students. Modern Preventive Medicine, vol.21, pp.4419-4420+4425, 2011.

[3] YU Kun. The Lack and Construction of the Leisure Education in Colleges and Universities. China Youth Study.vol.03, pp.103-105,2009. (in Chinese) 
[4] JI Hai-qun. The Present Situation, Characteristics and Countermeasures of College Students 'Leisure Life: From the Perspective of Internet Use, Jiangsu Social Sciences.vol.03,pp.90-95,2013. (in Chinese)

[5] ZHAO Li-na. A Study on the After-school Life of College Students. Education for Chinese After-school(Theory). vol.10, pp.23-24,2009. (in Chinese) 